\title{
Math anxiety and its relationship to inhibitory abilities and perceived emotional intelligence
}

\author{
María-José Justicia-Galiano*, Santiago Pelegrina, María-Teresa Lechuga, Nicolás Gutiérrez-Palma, Eva-María Martín-Puga, \\ and Cristina Lendínez
}

Universidad de Jaén (Spain).

\begin{abstract}
Título: Ansiedad matemática y su relación con capacidades inhibitorias e inteligencia emocional percibida.

Resumen: La ansiedad a las matemáticas es un problema emocional que repercute negativamente en el rendimiento académico de los estudiantes en distintos niveles educativos. El presente estudio analiza la relación entre este tipo de ansiedad y ciertos procesos cognitivos y emocionales. En primer lugar se pretendía determinar la relación entre la ansiedad a las matemáticas y ciertas habilidades inhibitorias dirigidas a eliminar o evitar el acceso a la conciencia de pensamientos intrusivos. En segundo lugar, interesaba comprobar la posible relación de la ansiedad a las matemáticas con la propia percepción del estudiante de sus habilidades emocionales. A tal fin se administraron a 187 estudiantes de primer curso del Grado de Psicología diferentes medidas de ansiedad a las matemáticas, a la estadística, de habilidades inhibitorias y de inteligencia emocional percibida. Los resultados mostraron que los estudiantes con puntuaciones más altas en ansiedad a las matemáticas presentaban una mayor susceptibilidad a experimentar pensamientos intrusivos, una menor eficacia a la hora de suprimirlos así como puntuaciones inferiores en comprensión y regulación de sus emociones. Los procesos inhibitorios y emocionales estudiados pueden resultar útiles para entender la naturaleza de la ansiedad matemática.

Palabras clave: Ansiedad matemática; inhibición; pensamientos intrusivos; inteligencia emocional percibida.
\end{abstract}

\section{Introduction}

Math anxiety can be defined as a feeling of tension and anxiety that interferes with the manipulation of numbers and the solving of mathematical problems in a wide variety of everyday and academic situations (Richardson \& Suinn, 1972). Thus, it would be a particular type of anxiety of a specific situational nature, directly associated with the learning of mathematical content.

Students suffering from this type of anxiety underperform academically in mathematics at elementary school (Vukovic, Kieffer, Bailey, \& Harari, 2013), high school (Lee, 2009) as well as at College and University levels (Hembree, 1990). They also exhibit different maladaptive behaviours such as not turning up to math class or avoiding selecting courses involving maths (Ashcraft \& Krause, 2007). Given these adverse effects of math anxiety, it is important to understand its nature and to determine its relationships to certain cognitive and emotional mechanisms that underlie other forms of anxiety. This study specifically addresses irrelevant and negative thoughts and the perception of one's own emotional abilities.

* Dirección para correspondencia [Correspondence address]:

$\mathrm{M}^{\mathrm{a}}$ José Justicia Galiano. Departamento de Psicología. Área de Evolutiva y de la Educación. Universidad de Jaén. Campus de las Lagunillas s/n, Edificio C5, Despacho-160. 23071 Jaén (España).

E-mail: mgaliano@ujaen.es
Abstract: Math anxiety has been found to be an emotional problem that has a negative effect on students' academic performance across different levels of education. This type of anxiety could be related to certain cognitive and emotional processes. A first objective was to examine the relationship between math anxiety and certain inhibitory abilities responsible of eliminating intrusive thoughts or preventing them access to consciousness. A second aim was to determine the extent in which math anxiety and students' self-perceptions of their own emotional abilities are related. To this end, 187 first-year undergraduate psychology students were administered different measures to assess math anxiety, statistics anxiety, inhibitory abilities, and perceived emotional intelligence. The results showed that students with high math anxiety were more likely to experience intrusive thoughts, were less effective at suppressing these thoughts, and reported lower scores in understanding and regulating their emotions. These cognitive mechanisms and emotional abilities are of relevance to better understand the nature of this type of anxiety.

Key words: Math anxiety; inhibition; intrusive thoughts; perceived emotional intelligence.

People who feel anxiety in mathematical situations are more likely to have intrusive thoughts that arise suddenly, involuntarily and repeatedly (Wigfield \& Meece, 1988). These thoughts tend to reflect worries and fear of failing, and usually are associated with a subjective report of certain unease. Greater susceptibility to intrusive thoughts may be rooted in the difficulty to suppress or inhibit these thoughts (Becker, Rinck, Roth, \& Margraf, 1998). This obstacle would be most evident in aversive situations, such as those that involve dealing with tasks, exercises and math tests.

Inhibition may be not a unitary mechanism. In fact, Hasher, Lustig and Zacks (2007) distinguish between two types of inhibitory processes that are of relevance in this context: a) those whose function is to stop irrelevant or distracting thoughts from gaining access to consciousness; and b) those processes responsible for removing these negative thoughts once they have entered consciousness. As regards the first type, irrelevant thoughts would cause a reduction in the working memory's effective capacity, as it would be partially devoted to attend to these intrusive thoughts (Eysenck \& Calvo, 1992; Eysenck, Derakshan, Santos, \& Calvo, 2007). In support of this view, Ashcraft and Kirk (2001) found that when comparing math-anxious university students with other non-anxious students, the former group performed worse on a working memory task involving numbers.

As for the second type of inhibitory mechanism, intrusions may be also due to the difficulty in diverting attention away from negative thoughts (Hopko, Ashcraft, Gute, Ruggiero, \& Lewis, 1998), which eventually would lead to a re- 
duction in the effective working memory capacity required to perform the mathematical task at hand. Thus, it is possible that this mechanism responsible for eliminating those negative thoughts that enter consciousness is compromised in people with math anxiety. Given that previous studies have been mainly focused on the first type of process (e.g. Ashcraft \& Kirk, 2001; Hopko et al., 1998), this study aims to obtain indices for both mechanism types in order to establish their relationship with math anxiety.

The appearance of intrusive thoughts and negative emotions associated with anxiety may be modulated or even counteracted by the way in which the person deal with emotionally negative situations, and also through the perception he or she has of their emotional abilities in these contexts. In this respect, the concept of emotional intelligence has proven to be useful in explaining how people process information regarding their own emotions and how they use this information to guide their thinking and behaviour in different situations. Emotional intelligence refers to the ability to attend emotions, understand their meaning, maximize their informative value and handle emotions appropriately (Mayer, Salovey, \& Caruso, 2004, 2008).

One of the instruments used to measure Emotional Intelligence is the shortened Spanish version of the wellknown Trait Meta-Mood Scale (Salovey, Mayer, Goldman, Turvey, \& Palfai, 1995) (TMMS-24) (Fernández-Berrocal, Extremera, \& Ramos, 2004). This questionnaire assesses three aspects of perceived emotional intelligence (PEI). The first is attention, which indicates just how much people believe they attend to and appraise their emotions. People who are more prone to attend to their emotional states are more likely to become distracted, focusing on their emotional reactions during an aversive situation. The second dimension is clarity, which involves the perceived ability to identify and distinguish specific emotions experienced in a particular situation. In general, people know whether they are feeling good or bad, but there are individual differences when it comes to determining, for example, if a negative feeling is anxiety, frustration, or anger. The last dimension is repair; this has to do with an individual's perception of their ability to effectively regulate their emotions, for example, thinking positive thoughts.

Some studies focused on other types of anxiety have found that students who are more able to perceive, understand and adequately regulate their emotions experience less anxiety (Extremera \& Fernández-Berrocal, 2006). It would be also expected this to be the case in situations related to math learning. However, to our knowledge there are no studies that have specifically addressed the possible link between emotional intelligence and math-specific anxiety.

There is also a possibility that perceived emotional intelligence is related to inhibitory control in anxious situations. However, how the different facets of emotional intelligence relate to intrusions remains unclear. Some studies focused on other forms of anxiety have reported a relationship between emotional clarity and a lower number of intrusive thoughts following an experimentally induced stressful situation (Salovey et al., 1995), while others have found that emotional regulation is associated with fewer intrusions (Ramos, Fernández-Berrocal, \& Extremera, 2007). Finally, a high level of attention to one's own emotions has been identified as an antecedent of rumination (Fernández-Berrocal \& Extremera, 2008; Hervás \& Vázquez, 2006; Thayer, Rossy, Ruiz-Padial, \& Johnsen, 2003). In sum, various studies have found that different aspects of PEI are related to the tendency to exhibit intrusive thoughts.

This study was aimed to explore the relationship between certain cognitive and emotional abilities and math anxiety. Thus, a first objective was to establish to what extent math anxiety is related to certain abilities to inhibit or suppress intrusive thoughts. To this end, measures of the two types of inhibitory mechanisms were considered: those that prevent irrelevant thoughts from entering consciousness and those responsible for removing those negative thoughts that have already gained access. It was expected that those students who exhibit greater levels of math anxiety would be more susceptible to experience intrusive thoughts and were less effective at suppressing them. Thus, these characteristics would leave them vulnerable to the anxiety felt in mathbased situations.

A second goal was to identify possible relationships between perceived emotional intelligence and math anxiety. It could be expected math-anxious students to show less competence when it comes to interpreting and confronting negative emotions. Furthermore, they would tend to pay more attention to their negative emotions which in turn would lead to more difficulty in understanding and regulating them.

\section{Methods}

\section{Participants}

187 first-year undergraduate psychology students (149 females) aged 18 to 52 years $(M=19.84 ; S D=4.47)$ participated in this study. For some measures the sample was reduced to 161 students, given that 26 students did not attended to the corresponding exam. All participants took part in exchange for course credit.

\section{Materials and procedure}

The following questionnaires were used for the purpose of this research.

Math anxiety. Math anxiety was assessed using a Spanish adaptation of the Revised Mathematics Anxiety Rating Scale (MARS-R; Plake \& Parker, 1982). This 24-item questionnaire, which uses a 5 -point Likert scale, evaluates anxiety in math-related academic situations (e.g., looking through the pages of a math book). The scale's internal consistency obtained in this study was .95 .

Because statistics, a math-related course, is part of the degree in psychology, the Statistical Anxiety Scale (SAS; Vig- 
il-Colet, Lorenzo-Seva, \& Condon, 2008, see also Oliver, Sancho, Galiana, \& Cebrià, 2014), was further included in the study. This scale comprises 24 items with questions on a 5-point scale that cover different scenarios related to statistical subjects (e.g., statistics makes me feel uncomfortable and anxious). The internal consistency obtained in this study was .95 .

Inbibitory abilities. Two self-report questionnaires related to two types of inhibition were used to assess inhibitory abilities. The White Bear Suppression Inventory (WBSI; Wegner \& Zanakos, 1994) measures the tendency to suppress thoughts as well as the appearance of unwanted thoughts. It comprises 15 items (e.g., I have thoughts that I cannot stop), and uses a 5 -point Likert-type scale. It has been proposed that this instrument includes two factors (Höping \& De Jong-Meyer, 2003). The first measures the suppression of thoughts while the second captures the subjective experience of having intrusive thoughts. The Cronbach's alpha values obtained were .83 for the first factor and .85 for the second.

The second self-report measure used was the Cognitive Failures Questionnaire (CFQ; Broadbent, Cooper, Fitzgerald $\&$ Parkes, 1982). It assesses the non-intentional thinking and behaviour mistakes made during everyday activities that have no bearing on the specific task being performed. The score is considered a measure of the susceptibility to becoming distracted by irrelevant thoughts accessing consciousness (Friedman \& Miyake, 2004) and is related to task performance which requires the inhibition of unwanted thoughts (Groome \& Grant, 2005). The questionnaire comprises 25 items, where participants have to rate on a 5 -point scale how often they have experienced diverse mistakes over the last six months. The internal consistency obtained in this study was .88.
Perceived Emotional Intelligence (PEI). To assess PEI, we used the Spanish modified version of the TMMS (Fernández-Berrocal et al., 2004). It is a widely used questionnaire that evaluates the meta-knowledge of emotional states organized around three factors: attention, clarity and repair. The questionnaire consists of 24 items, where participants are asked to rate their agreement on a 5 -point scale. The internal consistency coefficients obtained in this study were: .88 for the attention subscale, .87 for the clarity subscale, and .85 for the repair subscale.

Academic performance. Academic performance was measured by taking the students' final grades for two first-year academic courses: "Data Analysis I", which includes mathematical content, specifically concepts, analysis and statistical methods; and "Socioemotional Development", which covers the main stages and processes of human social and emotional development and, therefore, does not entail mathematical or statistical concepts.

\section{Procedure}

Questionnaires were administered collectively in a onehour session at the beginning of the semester. The participants' informed consent to take part in the study as well as to access their academic records at the end of the semester were obtained.

\section{Results}

Correlation analyses among the different measures and descriptive statistic are presented in Table 1.

Table 1. Descriptive statistics and correlation matrix for all the measures.

\begin{tabular}{|c|c|c|c|c|c|c|c|c|c|c|c|c|}
\hline & $M$ & $S D$ & 1 & 2 & 3 & 4 & 5 & 6 & 7 & 8 & 9 & 10 \\
\hline \multicolumn{13}{|l|}{ Academic Performance } \\
\hline 1. Socioemotional D. & 5.46 & 1.88 & - & & & & & & & & & \\
\hline 2 Data Analysis & 4.40 & 2.56 & $.44^{* *}$ & - & & & & & & & & \\
\hline \multicolumn{13}{|l|}{ Anxiety } \\
\hline 3. Math Anxiety & 67.17 & 16.80 & -.02 & $-.22 * *$ & - & & & & & & & \\
\hline 4 Statistical Anxiety & 72.41 & 16.53 & -.11 & $-.19 *$ & $.69 * *$ & - & & & & & & \\
\hline \multicolumn{13}{|l|}{ Inbibition } \\
\hline 5. Thought Intrusion & 26.98 & 6.23 & .09 & .01 & $.20^{* *}$ & $.24^{* *}$ & - & & & & & \\
\hline 6. Thought Suppression & 24.54 & 5.88 & .14 & .03 & $.24 * *$ & $.29 * *$ & $.77^{* *}$ & - & & & & \\
\hline 7. Cognitive Failures & 80.67 & 13.22 & -.08 & -.02 & $.27 * *$ & $.27 * *$ & $.33 * *$ & $.22^{* *}$ & - & & & \\
\hline \multicolumn{13}{|l|}{ PEI } \\
\hline 8. Attention & 26.53 & 6.07 & -.05 & .05 & .04 & .11 & $.41^{* *}$ & $.31^{* *}$ & $.22 * *$ & & & \\
\hline 9. Clarity & 27.30 & 5.73 & .11 & .09 & $-.26 * *$ & $-.25^{* *}$ &.$-19 * *$ & $-.19 * *$ & $-.22 * *$ & $.16^{*}$ & - & \\
\hline 10. Repair & 26.91 & 6.32 & .01 & .08 & -.14 & $-.22 * *$ & $-.16^{*}$ & -.06 & -.14 & .14 & $.45^{* *}$ & - \\
\hline
\end{tabular}
Note: $* p<.05, * * p<.01$.

An initial step was to determine whether anxiety is related to academic performance, and whether this relation depends on the type of academic subject: math or non-math related. The two anxiety measures correlated with the grades obtained in the course with statistical content (Data Analysis) $(r=-.158, p<.01$, in both cases). In contrast, these measures did not correlate with the math-free course (Socioemotional Development). These results confirm the specificity of the relationship between the level of anxiety reported by the participants and their performance in math-based tasks, but not in other types of content. The later negative relationship coincides with that found, also in our context 
with similar statistical contents by Núñez-Peña, SuárezPellicioni and Bono (2013).

The two anxiety measures were moderately correlated with the measures of cognitive inhibition: thought intrusions, thought suppression and cognitive failures. As regards to the PEI measures, significant correlations were only found between clarity and both anxiety measures and between emotional repair and statistics anxiety.

\section{Inhibitory abilities and anxiety}

In order to determine the amount of variance explained by the inhibitory abilities in the different anxiety measures, a series of multiple regression analyses were conducted, where math anxiety and statistics anxiety were the criterion variables and inhibitory abilities and the different PEI dimensions were the predictor variables. As shown in Table 2, two of the inhibitory variables, namely thought suppression and cognitive failures, were found to be significant predictors of both anxiety measures, accounting for $11.3 \%$ of the variance in math anxiety scores, $F(3,183)=7.74, p<.001$. Intrusive thought was not statistically significant. Similar results were obtained for statistics anxiety, where thought suppression and cognitive failures accounted for $13 \%$ of its variance, $F(3,183)=8.88, p<.001$.

Table 2. Regression analyses predicting math anxiety and statistical anxiety from inhibitory abilities and perceived emotional intelligence.

\begin{tabular}{|c|c|c|c|c|c|c|c|c|}
\hline & \multicolumn{4}{|c|}{ Math Anxiety } & \multicolumn{4}{|c|}{ Statistical Anxiety } \\
\hline & $\mathrm{R}^{2}$ & $\beta$ & $T$ & Sig & $\mathrm{R}^{2}$ & $\beta$ & $T$ & Sig \\
\hline Inbibition & .11 & & & & .13 & & & \\
\hline Thought Intrusion & & -.07 & -.65 & .514 & & -.04 & -.38 & .698 \\
\hline Thought Suppression & & .25 & 2.27 & .007 & & .27 & 2.54 & .012 \\
\hline Cognitive Failures & & .24 & 3.30 & .001 & & .22 & 3.00 & .003 \\
\hline PEI & .07 & & & & .10 & & & \\
\hline Attention & & .08 & 1.17 & .244 & & .17 & 2.35 & .020 \\
\hline Clarity & & -.25 & -3.15 & .000 & & -.21 & -2.64 & .009 \\
\hline Repair & & -.04 & -.51 & .614 & & -.14 & -1.84 & .067 \\
\hline
\end{tabular}

\section{PEI and anxiety}

An analogous set of multiple regression analyses were performed with math anxiety as criterion variables and the different dimensions of PEI as predictor variables. As can be seen in Table 2, in the case of PEI, clarity was the only significant predictor of math anxiety, accounting for $7.4 \%$ of its variance, $F(3,183)=4.88, p=.003$. On the other hand, both attention and clarity proved to be significant predictors of statistics anxiety, together explaining $10.2 \%$ of its variance, $F(3,183)=6.92, p<.001$. It should be noted that attention did not correlate significantly with any of the anxiety measures. Thus, the statistically significant beta weight obtained in regression analysis suggests that attention may be acting as a suppressor variable. That is, attention shares no variance directly with the anxiety measures but contributes to the regression equations by removing some irrelevant variance from the other predictor variable, namely clarity, to which it is also related.

\section{PEI and inhibitory abilities}

This study provided the opportunity to determine the relationship between the different dimensions of PEI and those of inhibitory ability. To this end, a series of multiple regression analyses were conducted, which included the different PEI measures as predictor variables and the inhibitory measures as the criterion ones. The results showed that attention and clarity predicted, to some degree, all of the inhibitory variables (see Table 3 ). That is, both attention and clarity were found to be significant predictors of intrusive thoughts, accounting for $25.2 \%$ of its variance, $F(3,183)=$ 20.51, $p<.001$. As for thought suppression, attention and clarity once again explained $15.7 \%$ of the variance, $F(3,183)$ $=11.38, p<.001$. Finally, the measure of cognitive failures was predicted by attention and clarity, which together accounted for $11.6 \%$ of its variance, $F(3,183)=8.04, p<.001$.

Table 3. Regression analyses predicting inhibitory abilities from perceived emotional intelligence.

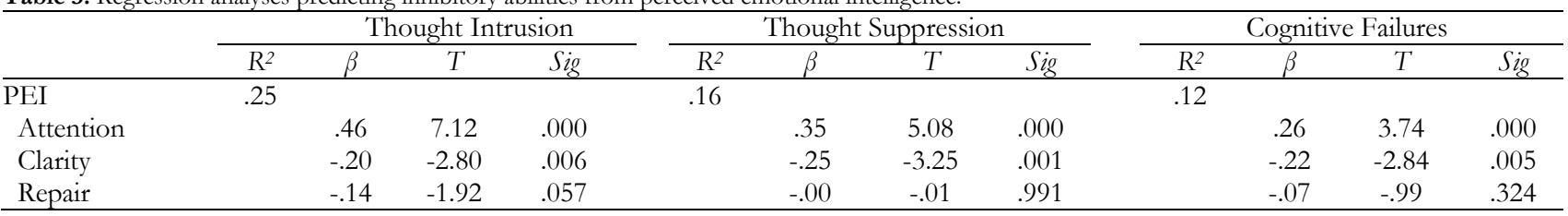




\section{Discussion}

Anxiety is a major emotional problem that has a negative effect on math learning at different educational levels. The main objective of this study was to examine two cognitive and emotional processes that may be associated with this type of anxiety. Specifically, we sought to determine the extent to which math anxiety is related to certain difficulties when it comes to inhibiting and suppressing associated intrusive thoughts. We also aimed to identify which aspects of students' PEI may be associated with math anxiety experienced by them. The results show that there are indeed different relationships among inhibitory measures, aspects of PEI, and math anxiety.

A relationship has been shown between inhibition and math anxiety. Following an approach based in Hasher et al.'s (2007) proposal, two types of inhibitory mechanisms were assessed: the first prevents irrelevant information or distracting thoughts from gaining access to consciousness, while the second is responsible for removing those negative thoughts once they have entered consciousness. Results reported a significant association between the level of anxiety experienced and the scores obtained in the cognitive failures questionnaire. Therefore, students with high math anxiety are more likely to get distracted during everyday activities, something which could also be generalized to academic tasks. A greater susceptibility to distracting thoughts would divert the person from following the course of action required in order to perform the task. These findings are consistent with those obtained previously with another methodology (see Ashcraft \& Krause, 2007, for a review). In these studies inhibition difficulties were inferred based on the performance scores obtained in working memory tasks. Thus, the results obtained here, using a self-assessment of inhibitory abilities, would provide further evidence of the relationship between inhibition and math anxiety.

The results for the second type of inhibition show that both math anxiety and statistics anxiety are related to the thought suppression measure. That is, students with higher anxiety scores were more likely to report unwanted intrusive thoughts as well as make more effort to remove or eliminate negative thoughts from consciousness. Both inhibitory aspects were closely related and, in fact, the thought suppression dimension is the only one that remains significant when both aspects are used simultaneously to predict the two anxiety measures. This may suggest that there is a common underlying factor for both dimensions, as argued by other authors (Muris, Merckelbach, \& Horselenberg, 1996).

In short, the data obtained indicate that math anxiety is related to the ability to inhibit irrelevant and negative thoughts that could be caused by specific worries. This is in line with results reported in other studies centred on general anxiety and other types of anxiety (Erskine, Kvavilashvili, \& Kornbrot, 2007; Muris et al., 1996). Consequently, this association may be also generalized to math anxiety. It is important to note that the relationships found in this study were observed in a neutral context, without any mathematical connotation. It would therefore be relevant to directly assess intrusive thoughts in more anxious situations, where students have to deal with mathematical tasks.

The second objective of this study was to assess those PEI dimensions associated with math anxiety. In this regard, it has been shown that the different facets of PEI relate differently to math anxiety. Students who scored lower in emotional clarity scored higher in measures of math anxiety. This result suggests that students who find more difficult to process and understand their emotions properly tend to perceive them more negatively. At the same time, they may be less capable of facing them appropriately, which would contribute to the appearance of intrusive thoughts. This is consistent with the association found in this study between clarity and the inhibitory measures. Thus, students with the lowest clarity scores reported more intrusive thoughts and greater attempts at suppressing them. Salovey et al. (1995) have previously showed that people who claim to have a clear understanding of their feelings fare better at recovering from the induced negative emotional state, as well as report a lower rate of intrusive thoughts, which is consistent with the relationship obtained in this study.

Another relevant result shows that the repair dimension of PEI predicts math anxiety. Specifically, students who are less able to repair their negative emotional states exhibit greater statistics anxiety. Previous studies have found some associations between a lack of perceived control and other types of anxiety, such as social anxiety (Hofmann, 2005) and generalized anxiety (Frala, Leen-Feldner, Blumenthal, \& Barreto, 2010). The results obtained in this research suggests that the perception of a lack of control could lead students to experience greater levels of anxiety when faced with situations they perceive as threatening or difficult to manage, as is the case of solving statistical problems. In a failed attempt to increase their sense of control, these students end up implementing ineffective strategies or coping styles such as worry (Mennin, Heimberg, Turk, \& Fresco, 2002), selfblame and self-focused rumination coping styles (Piemontesi, Heredia, Furlan, Sánchez-Rosas, \& Martínez, 2012). This interpretation is also consistent with the observation obtained in this study that students who reported a higher difficult to repair their negative emotional states indicate a greater number of intrusive thoughts (see also, Ramos et al., 2007, for a similar result).

Several limitations in the current study suggest caution in interpreting these findings. Firstly, these results may be generalized only to psychology student populations. Students with higher anxiety levels could have chosen to study other degrees without statistical courses. Therefore, the sample of this study could be biased towards lower levels of math anxiety. Other limitation is that only measures related to math anxiety were used. Although math anxiety may be considered as different from general anxiety (Ma, 1999), both types of anxiety moderately correlate (e.g., Núñez-Peña, SuárezPellicioni, Guilera, \& Mercadé-Carranza, 2013). Therefore, it 
would have been relevant to determine the extent in which the results obtained are similar for both general and math anxiety. Finally, this study follows a cross-sectional design, limiting the possibility of making causal interpretations. Future research should use a more causal methodology, as longitudinal designs.

In summary, the results of this study show relationships between math anxiety and certain inhibitory and emotional abilities. To our knowledge there are no previous studies that have specifically examined the link between PEI and math anxiety, meaning that these results constitute a novel

\section{References}

Ashcraft, M. H., \& Kirk, E. P. (2001). The relationships among working memory, math anxiety, and performance. Journal of Experimental Psychology: General, 130, 224-237.

Ashcraft, M. H., \& Krause, J. A. (2007). Working memory, math performance and math anxiety. Psychonomic Bulletin and Review, 12, 243-248.

Becker, E. S., Rinck, M., Roth, W. T., \& Margraf, J. (1998). Don't worry and beware of white bears: Thought suppression in anxiety patients. Journal of Anxiety Disorders, 12, 39-55.

Broadbent, D. E., Cooper, P. F., Fitzgerald, P., \& Parkes, K. R. (1982). The Cognitive Failures Questionnaire (CFQ) and its correlates. British Journal of Clinical Psychology, 21, 1-16.

Erskine, J. A. K., Kvavilashvili, L., \& Kornbrot, D. E. (2007). The predictors of thought suppression in young and old adults: Effects of rumination, anxiety, and other variables. Personality and Individual Differences 42, 10471057.

Extremera, N., \& Fernández-Berrocal, P, (2006). Emotional intelligence as predictor of mental, social, and physical health in university students. Spanish Journal of Psychology, 9, 45-51.

Eysenck, M. W., \& Calvo, M. G. (1992). Anxiety and Performance: The processing efficiency theory. Cognition and Emotion, 6, 409-434.

Eysenck, M. W., Derakshan, N., Santos, R., \& Calvo, M. G. (2007). Anxiety and cognitive performance: Attentional control theory. Emotion, 7, 336353.

Fernández-Berrocal, P., Alcaide, R., Extremera, N., \& Pizarro, D. A. (2006). The role of emotional intelligence in anxiety and depression among adolescents. Individual Differences Research, 4, 16-27.

Fernández-Berrocal, P., \& Extremera, N. (2008). A review of trait metamood research. In A. M. Columbus (Ed.), Advances in Psychology Research (Vol. 55, pp. 17-45). Nueva York: Nova Publishers.

Fernández-Berrocal, P., Extremera, N., \& Ramos, N. (2004). Validity and reliability of the Spanish version of the White Bear Suppression Inventory. Psychological Reports, 94, 782-784.

Frala, J. L., Leen-Feldner, E. W., Blumenthal, H., \& Barreto, C. C. (2010). Relations among perceived control over anxiety-related events, worry, and Generalized Anxiety Disorder in a sample of adolescents. Journal of Abnormal Child Psychology, 38, 237-247.

Friedman, N. P., \& Miyake, A. (2004). The relations among inhibition and interference control functions: a latent variable analysis. Journal of Experimental Psychology: General, 133, 101-135.

Groome, D., \& Grant, N. (2005). Retrieval-induced forgetting is inversely related to everyday cognitive failures. British Journal of Psychology, 96, 313319.

Hasher, L., Lustig, C., \& Zacks, R. (2007). Inhibitory mechanisms and the control of attention. In A. Conway, C. Jarrold, M. Kane, A. Miyake, \& J. Towse (Eds.), Variation in working memory. New York: Oxford University Press.

Hembree, R. (1990). The nature, effects and relief of mathematics anxiety. Journal for Research in Mathematics Education, 21, 33-46.

Hervás, G., \& Vázquez, C. (2006). Explorando el origen emocional de las respuestas rumiativas: El papel de la complejidad emocional y la inteligencia emocional. Ansiedad y Estrés, 12, 279-292. approach to the study of factors involved in math anxiety. These results can be added to those obtained for other types of anxiety, such as generalized anxiety (Extremera \& Fernández-Berrocal, 2006; Fernández-Berrocal, Alcaide, Extremera, \& Pizarrro, 2006) and social anxiety (e.g., Turk, Heimberg, Luterek, Mennin, \& Fresco, 2005). A greater understanding of the mechanisms that lead to the appearance of math anxiety and its negative symptoms can facilitate advances not only on a theoretical level, but also on a practical level, by promoting specific training programs to mitigate its adverse effects.

Hofmann, S. G. (2005). Perception of control over anxiety mediates the relation between catastrophic thinking and social anxiety in social phobia. Behaviour Research and Therapy, 43, 885-895.

Höping, W., \& De Jong-Meyer, R. (2003). Differentiating unwanted intrusive thoughts from thought suppression: what does the White Bear Suppression Inventory measure? Personality and Individual Differences, 34, 1049-1055.

Hopko, D. R., Ashcraft, M. H, Gute, J., Ruggiero, K. J., \& Lewis, C. (1998). Mathematics anxiety and working memory: Support for the existence of a deficient inhibition mechanism. Journal of Anxiety Disorders, 12, 343 355.

Lee, J. (2009). Universals and specifics of math self-concept, math selfefficacy and math anxiety across 41 PISA 2003 participating countries. Learning and Individual Differences, 19, 355-365.

Ma, X. (1999). A meta-analysis of the relationship between anxiety toward Mathematics and achievement in mathematics. Journal for Research in Mathematics Education, 30(5), 520-540.

Mayer, J. D., Salovey, P., \& Caruso, D. R. (2004). Emotional Intelligence: Theory, findings and implications. Psychological Inquiry, 15, 197-215.

Mayer, J. D., Salovey, P., \& Caruso, D. R. (2008). Emotional Intelligence: New ability or eclectic trait? American Psychologist, 63, 503-517.

Mennin, D. S., Heimberg, R. G., Turk, C. L., \& Fresco, D. M. (2002). Applying an emotion regulation framework to integrative approaches to generalized anxiety disorder. Clinical Psychology: Science and Practice, 9, 85-90.

Muris, P., Merckelbach, H., \& Horselenberg, R. (1996). Individual differences in thought suppression: the White Bear Suppression Inventory: factor structure, reliability, validity and correlates. Behaviour Research and Therapy, 34, 501-513.

Núñez-Peña, M.I., Suárez-Pellicioni, M., \& Bono, R. (2013). Effects of math anxiety on student success in higher education. International Journal of Educational Research, 58, 36-43.

Núñez-Peña, M.I., Suárez-Pellicioni, M., Guilera, G., \& Mercadé-Carranza, C. (2013). A Spanish version of the short Mathematics Anxiety Rating Scale (sMARS). Learning and Individual Differences, 24, 204-210.

Oliver, A., Sancho, P., Galiana, L. \& Cebrià, M. A. (2014). Nueva evidencia sobre la Statistical Anxiety Scale (SAS). Anales de Psicología, 30, 150-156.

Piemontesi, S.E., Heredia, D.E., Furlan, L.A., Sánchez-Rosas, J., \& Martínez, M. (2012). Ansiedad ante los exámenes y estilos de afrontamiento ante el estrés académico en estudiantes universitarios. Anales de Psicología, 28, 89-96.

Plake, B. S., \& Parker, C. S. (1982). The development and validation of a revised version of the Mathematics Anxiety Rating Scale. Educational and Psychological Measurement, 42, 551-557.

Ramos, N., Fernández-Berrocal, P., \& Extremera, N. (2007). Perceived emotional intelligence facilitates cognitive-emotional processes of adaptation to an acute stressor. Cognition and Emotion, 21, 758-772.

Richardson, F. C., \& Suinn, R. M. (1972). The mathematics anxiety rating scale: Psychometrics data. Journal of Counseling Psychology, 19, 551-554.

Salovey, P., Mayer, J. D., Goldman, S., Turvey, C., \& Palfai, T. (1995). Emotional attention, clarity, and repair: exploring emotional intelligence using the Trait Mood Scale. In J. W. Pennebaker (dir.), Emotion, disclosure 
and health (pp. 125-154). Washington, DC: American Psychological Association.

Thayer, J. F., Rossy, L. A., Ruiz-Padial, E., \& Johnsen, B. H. (2003). Gender differences in the relationship between emotional regulation and depressive symptoms. Cognitive Therapy and Research, 27, 349-364.

Turk, C. L., Heimberg, R. G., Luterek, J. A, Mennin, D. S., \& Fresco, D. M. (2005). Emotion dysregulation in Generalized Anxiety Disorder: A comparison with Social Anxiety Disorder. Cognitive Therapy and Research, 29, 89-106.

Vigil-Colet, A., Lorenzo-Seva, U., \& Condon, L. (2008). Development and validation of the Statistical Anxiety Scale. Psicothema, 20, 174-180.
Vukovic, R. K., Kieffer, M. J., Bailey, S. P., \& Harari, R. R. (2013). Mathematics anxiety in young children: Concurrent and longitudinal associations with mathematical performance. Contemporary Educational Psychology, $38,1-10$.

Wegner, D. M., \& Zanakos, S. (1994). Chronic thought suppression. Journal of Personality, 62, 616-640.

Wigfield, A., \& Meece, J. L. (1988). Math anxiety in elementary and secondary school students. Journal of Educational Psychology, 80, 210-216.

(Article received: 18-03-2014; revised: 09-07-2014; accepted: 21-08-2014) 